\title{
Análise fitoquímica e avaliação da susceptibilidade antimicrobiana de diferentes tipos de extratos de Plantago major L. (Plantaginaceae)
}

Phytochemical screening assessment and antimicrobial susceptibility of extracts from Plantago major L. (Plantaginaceae)

Recebido em: 25/12/2015

Aceito em: $\quad$ 09/03/2016
Paulo Augusto Oliveira VENTURA; João Paulo Oliveira JESUS; José Ribamar de Souza NOGUEIRA;

Alvaro Carlos GALDOS-RIVEROS

Faculdade de Farmácia de Brasília, Anhanguera Institucional Ltda. QS

1, rua 212, lotes 11,13 e 15.- Águas Claras, DF. CEP 71950-550, Brasil.

E-mail: alvarogaldos@usp.br

\begin{abstract}
Plantago major L. is a plant from the European continent, used for medicinal purposes. It presents hematopoietic activity, and has been in the treatment of leukemia, carcinoma and against viruses. Other activities include antiparasitic, diuretic, hepatoprotective and anti-inflammatory. Ttherefore, this study evaluated the phytochemical profile of aqueous, ethanol and hydroalcoholic extracts of Plantago major L. leaves, as well as the antimicrobial action to Gram-positive and Gramnegative strains. The results of the phytochemical analysis showed the presence of tannins, saponins, alkaloids, flavonoids, terpenes and glycosides. Antimicrobial analysis demonstrated ethanol extracts and hydroalcoholic of Plantago major L. have an antimicrobial action to Staphylococcus aureus, through the actions of bioactive metabolites with antimicrobial activity, such as tannins and flavonoids, which would become the Plantago major L. possible candidate for a new herbal medicine.
\end{abstract}

Keywords: tanchagem; microbial resistance; medicinal plants; antioxidant

\section{RESUMO}

Plantago major L. é uma planta oriunda do continente europeu, utilizada para fins medicinais. Apresenta atividade hematopoiética, atividade no tratamento de leucemias, carcinomas e contra vírus, bem como atividade antiparasitária, diurética, hepatoprotetora e anti-inflamatória. O presente trabalho avaliou o perfil fitoquímico dos extratos aquoso, etanólico e hidroalcoólico das folhas de Plantago major L., como também a ação antimicrobiana frente a bactérias Gram-positivas e Gram-negativas. Os resultados obtidos na análise fitoquímica demonstraram a presença de taninos, saponinas, alcaloides, flavonoides, terpenos e glicosídeos. A análise antimicrobiana mostrou que os extratos etanólico e hidroalcoólico de Plantago major L. possuem ação antimicrobiana frente ao Staphylococcus aureus, por meio da atuação de metabólitos bioativos com ação antimicrobiana, tais como taninos e flavonoides, o que torna Plantago major L. um possível candidato à obtenção de um novo fitoterápico.

Palavras-chave: tanchagem; resistência microbiana; plantas medicinais; antioxidante 


\section{INTRODUÇÃO}

O emprego de plantas na terapêutica provém de conhecimentos empíricos, acumulados durante milênios e passados pelas diversas gerações por meio da cultura popular (1). Há tempos a busca pela fitoterapia tem crescido por parte de pacientes, cientistas e serviços de saúde, e, de acordo com dados da OMS, $80 \%$ da população de países em desenvolvimento utilizam os recursos tradicionais em seus cuidados básicos e $85 \%$ utilizam plantas medicinais e produtos derivados destas (2).

Nos anos 1981 a 2002 cerca de $50 \%$ dos novos fármacos introduzidos no mercado mundial provinham de fontes naturais ou se originavam destes (3). De todos os municípios brasileiros, a fitoterapia é utilizada em 116 e abrange 22 unidades federadas, compondo as possibilidades de tratamento contidas no SUS (4).

Plantago major L. é uma planta de interesse medicinal pertencente à família Plantaginaceae, sendo conhecida popularmente como tanchagem, tansagem, transagem, tanchagem maior, llantén, plantagem ou língua de vaca. É procedente do continente europeu e espalhou-se pelo mundo, sendo possível a sua localização em diversos países da África, da Ásia e das Américas (5).

Possui raiz principal e raízes secundárias, sendo estas espessas e inconspícuas. Apresenta caule de 0,5-1,5 $\mathrm{cm}$ de altura, suas folhas são obovadas, com margens crenadas, glabras ou pilosas. Desenvolve inflorescência laxa com comprimento variando de 6,0 a $6,5 \mathrm{~cm}$ e de 7,0 a 9,0 $\mathrm{cm}$, com escapo sulcado e glabro, de forma inconspícua, medindo de 11,5 a 18,0 cm de comprimento. Exibe ovário bilocular e em cada lóculo há muitos óvulos. As sementes são irregulares, com testa rugosa e coloração castanho-escura (6).

Apresenta as seguintes propriedades terapêuticas: atividade hematopoiética (7), atividade no tratamento de leucemias, carcinomas e contra vírus (in vitro) (8), atividade antiparasitária in vitro (9), atividade diurética (10), atividade hepatoprotetora e anti-inflamatória (11), além de atividade antioxidante em neutrófilos (12).

Tais propriedades devem-se à presença de diferentes compostos, sendo estes carboidratos, lipídeos, alcaloides (indicaína e plantagonina), derivados do ácido cafeico, terpenos, glicosídeo de aucubina, flavonoides (baicaleína, apigenina), ácido ascórbico, ácido benzoico, ácido clorogênico, ácido cítrico, ácido ferúlico, ácido oleanólico, ácido salić́lico e ácido ursólico $(13,14)$.

O flavonoide baicaleína é apontado como responsável pela ação antioxidante e anti-inflamatória da planta $(15$, 16), bem como por induzir a morte de células de carcinoma (17) e inibir o crescimento de células de hepatoma (18), além de apresentar ação antiviral (19). O glicosídeo de aucubina atua também como agente anti-inflamatório (20). Os ácidos cafeico, ferúlico, clorogênico, oleanólico e ursólico são citados como agentes antitumorais in vitro $(21,22)$, e os ácidos oleanólico e ursólico estão relacionados ainda com a atividade hematopoiética da planta (23). De acordo com Chiang e cols. (2002), os ácidos ferúlico, cafeico e clorogênico foram responsáveis pela atividade antiviral in vitro do extrato aquoso de Plantago major L., dos quais o cafeico e o clorogênico demonstraram a mais forte atividade supracitada (8). Oliveira (2007) atribuiu a atividade antiparasitária de plantas aos alcaloides (24).

$\mathrm{O}$ crescente uso indiscriminado de fármacos antimicrobianos é uma das causas responsáveis pelo aparecimento de cepas bacterianas resistentes em escala mundial (25). Estudos vêm descobrindo microrganismos que conseguiram vencer a ação dos antimicrobianos convencionais e alguns são resistentes aos novos fármacos $(26,27)$. O aumento da resistência bacteriana provoca sérios problemas na saúde e economia de um país, portanto novas alternativas de antibióticos de amplo espectro são necessárias no combate a esses agentes. As espécies bacterianas resistentes recentemente chamadas de patógenos ESKAPE são: Enterococcus faecium, Staphylococcus aureus, Klebsiella pneumoniae, Acinetobacter baumanii, Pseudomonas aeruginosa e Enterobacter spp. (28), embora outras espécies de microrganismos tais como Streptococcus pyogenes e Salmonella typhimurium estejam entre os patógenos que causam cerca de 600 milhões de infecções por ano no mundo (29). Portanto, o presente estudo avaliou o perfil fitoquímico e susceptibilidade antimicrobiana dos extratos aquoso, hidroalcoólico e etanólico das folhas de Plantago major L. frente às bactérias Staphylococcus aureus, Streptococcus pyogenes, Salmonella typhimurium e Klebsiella pneumoniae.

\section{MATERIAL E MÉTODOS}

Material vegetal. As folhas de Plantago major $\mathrm{L}$. foram coletadas próximo à rodovia GO-547, no município de Santo Antônio do Descoberto, Goiás, no período de junho a agosto de 2014 (Figura 1A). Uma amostra do material vegetal foi identificada pela Botânica Prof ${ }^{a}$. MSc. Catarina Garofalo e uma exsicata depositada no Herbário da Faculdade Anhanguera de Brasília (FAB) sob o número de registro 27.2001. Após a coleta, as folhas foram submetidas a processo de desidratação in natura (Figura 1B) pelo período de dez dias.

Obtenção dos extratos etanólico, hidroalcoólico e aquoso. Os solventes mais utilizados pela população na elaboração de extratos de plantas são o álcool e a água, ou a mistura dos dois. Para obtenção dos extratos foi utilizada a metodologia de Nascimento (2012), com adaptações (30). Foram pesados $50 \mathrm{~g}$ de folhas desidratadas e moídas de Plantago major L., colocando-as em frasco de vidro contendo $450 \mathrm{~mL}$ de álcool etílico absoluto (99,5\%) para a obtenção do extrato etanólico. Para o extrato aquoso, foram pesados $40 \mathrm{~g}$ de folhas desidratadas e moídas da planta, 
colocando-as em frasco de vidro contendo $360 \mathrm{~mL}$ de água destilada. Outros $40 \mathrm{~g}$ das folhas desidratadas e moídas da planta foram colocados em frasco de vidro contendo $360 \mathrm{~mL}$ de solução hidroalcoólica (1:1) para obtenção do extrato hidroalcoólico. Foi utilizado o método de maceração durante sete dias, com agitação diária, revestindo-se os frascos com papel alumínio, a fim de se proteger o macerado de possíveis alterações por radiação visível. Os frascos ficaram acondicionados em geladeira à temperatura de $2-8^{\circ}$ C para conservação.

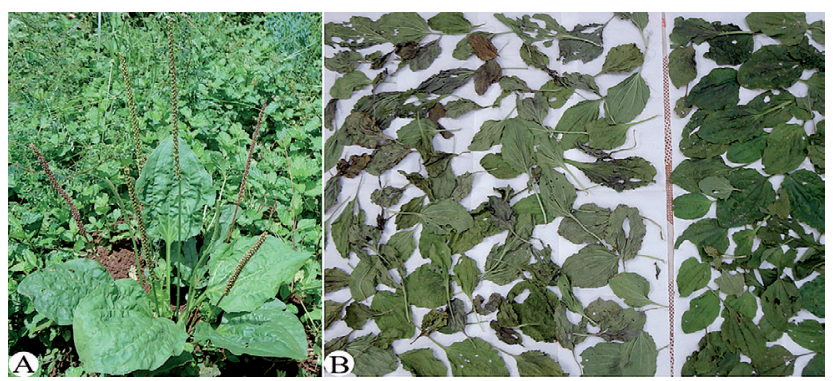

Figura 1 - Plantago major L. (A); folhas. Processo de desidratação in natura $(B)$.

Concluído o processo de maceração, os macerados foram submetidos à filtração, utilizando papel filtro pregueado, dando origem a três soluções extrativas. Essas soluções foram levadas ao rotaevaporador (Fisatom, modelo 801), ajustado à rotação de $40 \mathrm{rpm}$, à temperatura entre 92$110^{\circ} \mathrm{C}$, com o objetivo de retirar os solventes e impedir uma possível interferência destes no resultado dos testes fitoquímicos e antimicrobianos, concentrando até a obtenção de três tipos de extratos secos (etanólico, aquoso e hidroalcoólico).

O cálculo do rendimento dos extratos foi realizado dividindo o peso em gramas do extrato pelo peso em gramas da droga vegetal, multiplicando o valor obtido por 100, conforme metodologia de Almeida e cols. (2015) (31).

Análise fitoquímica qualitativa. Foi realizada análise fitoquímica qualitativa por meio de reações químicas de coloração, precipitação e formação de espuma de acordo com metodologia de Costa (2002) e Simões e cols. (2007), com adaptações $(19,32)$. Foi avaliada a possível presença de alcaloides, flavonoides, terpenos, glicosídeos, taninos (hidrolisáveis e condensados), antraquinonas e saponinas.

Atividade antimicrobiana. Para a análise antimicrobiana foram obtidos dois tipos distintos de cepa bacteriana: a concentrada, necessária para a revitalização das cepas liofilizadas, e a de trabalho (diluída), necessária para a realização dos testes de sensibilidade microbiana. As cepas liofilizadas padrão utilizadas foram: Staphylococcus aureus, ATCC 25923, Streptococcus pyogenes, ATCC 19615, Salmonella typhimurium, ATCC 123912, e Klebsiella pneumoniae, ATCC 13883.

Para revitalizar as cepas, $1 \mathrm{~mL}$ de solução de infusão cérebro-coração (BHI) esterilizada foi adicionado a cada um dos 4 frascos que continham a cepa bacteriana liofi- lizada, realizando homogeneização em cada frasco. Após, foram utilizados 04 tubos de ensaio com tampa rosqueável. Em cada tubo, foram adicionados $5 \mathrm{~mL}$ de solução BHI esterilizada. Em seguida, $50 \mu \mathrm{L}$ da cepa bacteriana revitalizada foram adicionados a cada um dos tubos, ou seja, uma espécie bacteriana diferente em cada tubo. O conteúdo dos tubos foi homogeneizado manualmente. Após a homogeneização, foram transferidos, de cada um dos tubos, $100 \mu \mathrm{L}$ da solução bacteriana para outros 4 tubos contendo em cada um $5 \mathrm{~mL}$ de solução de BHI esterilizada. Esses tubos foram levados para a estufa bacteriológica (Quimis, Q-316B3) a $35^{\circ} \mathrm{C} \pm 2^{\circ} \mathrm{C}$, por 24 horas, período necessário para o crescimento bacteriano, sendo obtida a cepa concentrada.

Para obter a cepa de trabalho utilizada na análise antimicrobiana, a cepa concentrada foi diluida até atingir a turvação equivalente ao tubo 0,5 da escala McFarland, que corresponde a $1,5 \times 10^{8} \mathrm{UFC} / \mathrm{mL}$. Para tanto, foi utilizada a técnica de Bauer e cols. (1966), com adaptações (33), esterilizando, por processo de autoclavação, 5 tubos de ensaio com tampa rosqueável contendo, cada um, $9 \mathrm{~mL}$ de solução salina $0,9 \%$. Aos tubos contendo a solução salina estéril foram adicionados $100 \mu \mathrm{L}$ da cepa concentrada das espécies bacterianas (cada tubo recebeu uma espécie bacteriana diferente), levando ao espectrômetro UV-Vis (Químis, Q-108 DP), com absorbância ajustada em $625 \mathrm{~nm}$, até ser obtida uma leitura entre 0,08 a $0,1 \mathrm{~nm}$, o que equivale à concentração da cepa contida no tubo 0,5 da escala McFarland, dando origem à cepa de trabalho.

Em seguida foram inoculados $100 \mu \mathrm{L}$ de cada uma das cepas de trabalho em placas de Petri distintas contendo meio de cultura ágar Mueller-Hinton (Biomerieux, lote:1408110706). A cultura foi estriada uniformemente em toda superfície da placa com o auxílio de um Swab estéril (LaborSwab, lote 020806A).

Após estriar as cepas nas placas, foram perfurados, com o auxílio de ponteiras estéreis, poços com $6 \mathrm{~mm}$ de diâmetro. Em cada placa de Petri foram perfurados de 3 a 4 poços. Cada um dos poços recebeu $100 \mu \mathrm{L}$ dos extratos em diluições específicas. O extrato etanólico foi diluído até a proporção 1:32; o extrato aquoso também foi diluído até a proporção 1:32; e o extrato hidroalcoólico foi diluído até a proporção 1:512;, com água destilada esterilizada. Para cada extrato, foram utilizadas placas distintas, que foram incubadas em estufa bacteriológica (Quimis), a $35^{\circ} \mathrm{C} \pm$ $2{ }^{\circ} \mathrm{C}$, por um período de 24 horas, segundo metodologia de Nascimento e cols. (2000), com adaptações (34). Após o período de incubação, foi observada a presença ou a ausência de halo de inibição. A medida dos halos, em milímetros, foi realizada por meio de paquímetro manual. Todos os testes foram realizados em duplicata.

O controle positivo foi selecionado apor meio de realização prévia de teste de sensibilidade para cada cepa bacteriana, o que permitiu utilizar o melhor controle em cada cepa. Foram testados os seguintes antimicrobianos 
de referência: amoxicilina $10 \mu$ g (lote: 30125053 ), cloranfenicol $30 \mu \mathrm{g}$ (lote: 21226052), tetraciclina $30 \mu \mathrm{g}$ (lote: 30228034) e vancomicina $30 \mu \mathrm{g}$ (lote: 30121054 ), todos provenientes do laboratório laborclin. Como controle negativo foi utilizada água destilada esterilizada.

\section{RESULTADOS E DISCUSSÃO}

O rendimento dos extratos secos provenientes das folhas de Plantago major L. em relação aos diferentes solventes utilizados para extração dos metabólitos foram: extrato hidroalcoólico $\left(\mathrm{EtH}_{2} \mathrm{O}, 18,8 \%\right)$; extrato etanólico (EtOH, 11\%); extrato aquoso $\left(\mathrm{H}_{2} \mathrm{O}, 9 \%\right)$.

Análise fitoquímica qualitativa. Os resultados da análise fitoquímica foram compilados de acordo com o exposto na Tabela 1, e corroboram estudos realizados por Samuelsen e cols. (1995), os quais demonstraram que o extrato hidroalcoólico (80\%) das folhas de Plantago major L. continham alcaloides, flavonoides, glicosídeos iridoides e terpenos (13), assim como os estudos realizados por Kawashty e cols. (1994), que descreveram a presença de vários tipos de flavonoides em extrato hidroalcoólico $(70 \%)$ das folhas e caule de Plantago major L. (35).

Não houve constatação da presença de antraquinonas, o que está de acordo com estudos dos autores supracitados, segundo os quais o referido metabólito secundário não compunha o perfil fitoquímico da planta, entretanto, em estudo feito por de Paula (2010) (36), por meio de análise fitoquímica preliminar em extrato metanólico de Plantago major L., foi identificada a presença de antraquinonas reduzidas.

Tabela1. Avaliação fitoquímica preliminar de extratos de folhas de Plantago major L

\begin{tabular}{|c|c|c|c|}
\hline \multirow{2}{*}{$\begin{array}{l}\text { Classes } \\
\text { químicas }\end{array}$} & \multicolumn{3}{|c|}{ Extrato } \\
\hline & EtOH & $\mathrm{EtH}_{2} \mathrm{O}(50 \%)$ & $\mathrm{H}_{2} \mathrm{O}$ \\
\hline Flavonoides & - & + & + \\
\hline Taninos & + & + & - \\
\hline Saponinas & + & - & - \\
\hline Terpenos & - & + & + \\
\hline Antraquinonas & - & - & - \\
\hline Glicosídeos & + & + & + \\
\hline Alcaloides & + & + & + \\
\hline
\end{tabular}

Susceptibilidade antimicrobiana. A cepa de Staphylococcus aureus mostrou ser sensível ao extrato hidroalcoólico das folhas de Plantago major L., o que corrobora testes realizados por Freitas e cols. (2002), que demonstrou a sensibilidade de doze amostras de Staphylococcus aureus frente ao extrato hidroalcoólico dessa planta (37), além de pesquisas relatadas por Samuelsen (2000), nas quais os extratos metanólico e hidroalcoólico $(70 \%$ e $50 \%$, respectivamente) das folhas de Plantago major L. foram eficazes contra esse microrganismo (10).

Essa bactéria demonstrou sensibilidade ao extrato etanólico das folhas de Plantago major L., o que está de acordo com estudos de Ansolini e cols. (2006), com extrato etanólico das folhas dessa planta contra diversas bactérias, incluindo Staphyloccocus aureus, obtendo uma inibição considerável (38).

De acordo com os resultados obtidos, os extratos etanólico e hidroalcoólico apresentaram ação antimicrobiana significativa contra Staphylococcus aureus. Foi constatado que o extrato hidroalcoólico exerceu um efeito inibitório até a diluição 1/128 $(0,6 \mathrm{mg} / 100 \mu \mathrm{L})$ comparado ao extrato etanólico. $\mathrm{O}$ extrato etanólico apresentou maior halo de inibição em sua concentração $1 / 1$ comparado ao extrato hidroalcoólico, sendo que sua atividade inibitória foi restrita à diluição $1 / 8(7 \mathrm{mg} / 100 \mu \mathrm{L})$, dando margem à hipótese de que o rendimento do extrato hidroalcoólico, por ter sido maior em relação ao etanólico, pode ter agrupado maior concentração de metabólitos secundários, possibilitando ação mesmo em maiores diluições. O extrato etanólico, por ter tido menor rendimento, apresentou ação em menores diluições, entretanto com maior halo de inibição, o que poderia ser justificado pelo tipo de solvente (etanol absoluto) que possivelmente interagiu de forma melhor com metabólitos, tais como os taninos, que detém ação antimicrobiana, produzindo maior halo de inibição comparado ao solvente hidroalcoólico (Tabela 2).

Os controles positivos utilizados com concentrações de antimicrobianos de referência foram: amoxicilina $10 \mu \mathrm{g}$ (lote: 30125053), cloranfenicol $30 \mu$ g (lote: 21226052) e tetraciclina $30 \mu \mathrm{g}$ (lote: 30228034 ). Esses apresentaram zonas de inibição variadas, entre $23-30 \mathrm{~mm}$. O controle negativo utilizado foi água destilada esterilizada, o qual não apresentou inibição (Tabela 3).

O extrato aquoso das folhas de Plantago major L. não apresentou inibição em nenhuma das concentrações, o que comprova pesquisas desenvolvidas por Samuelsen (2000) e Ansolini e cols. (2006), nas quais o referido extrato não demonstrou inibição frente a bactérias diversas, incluindo a Staphyloccocus aureus $(10,38)$. Os resultados desse trabalho estão de acordo também com estudo realizado por Tales \& Costa (2014), pelo qual o extrato aquoso, após análise microbiológica utilizando Staphyloccocus aureus, não apresentou atividade antimicrobiana. Segundo os autores, o resultado pode ser interpretado como uma falta de ação antimicrobiana ou concentração insuficiente do extrato (39). 
Tabela 2 - Atividade antimicrobiana de extratos de folhas de Plantago major contra Staphylococcus aureus.

\begin{tabular}{|c|c|c|c|c|c|c|}
\hline \multirow{2}{*}{$\begin{array}{l}\text { Extratos } \\
\text { Diluição }\end{array}$} & \multicolumn{2}{|c|}{ EtOH } & \multicolumn{2}{|c|}{$\mathrm{EtH}_{2} \mathrm{O}$} & \multicolumn{2}{|c|}{$\mathrm{H}_{2} \mathrm{O}$} \\
\hline & $(\mathrm{mg} / 100 \mu \mathrm{L})$ & $(\mathrm{mm})$ & $(\mathrm{mg} / 100 \mu \mathrm{L})$ & $(\mathrm{mm})$ & $(\mathrm{mg} / 100 \mu \mathrm{L})$ & $(\mathrm{mm})$ \\
\hline $1: 1$ & 56,0 & 24,0 & 76,0 & 20,2 & 36,0 & - \\
\hline $1: 2$ & 28,0 & 22,0 & 38,0 & 22,5 & 18,0 & - \\
\hline $1: 4$ & 14,0 & 17,5 & 19,0 & 22,2 & 9,0 & - \\
\hline $1: 8$ & 7,0 & 10,8 & 9,5 & 21,5 & 4,5 & - \\
\hline $1: 16$ & 3,5 & - & 4,75 & 18,8 & 2,3 & - \\
\hline $1: 32$ & 1,75 & - & 2,4 & 17,0 & 1,15 & - \\
\hline $1: 64$ & - & - & 1,2 & 15,5 & - & - \\
\hline $1: 128$ & - & - & 0,6 & 14,0 & - & - \\
\hline $1: 256$ & - & - & 0,3 & - & - & - \\
\hline $1: 512$ & - & - & 0,15 & - & - & - \\
\hline
\end{tabular}

Tabela 3 - Zona de inibição dos controles positivo e negativo utilizados no experimento.

\begin{tabular}{|l|l|l|l|l|}
\hline Bactérias & Controle positivo & Zona de inibição (mm) & Controle negativo & Zona de inibição (mm) \\
\hline S. aureus & Amoxicilina $10 \mu \mathrm{g}$ & 30 & $\mathrm{H}_{2} \mathrm{O}_{(\mathrm{p})}$ & - \\
\hline S. typhimurium & Tetraciclina $30 \mu \mathrm{g}$ & 23 & $\mathrm{H}_{2} \mathrm{O}_{(\mathrm{p})}$ & - \\
\hline S. pyogenes & Cloranfenicol $30 \mu \mathrm{g}$ & 28 & $\mathrm{H}_{2} \mathrm{O}_{(\mathrm{p})}$ & - \\
\hline K. pneumoniae & Tetraciclina $30 \mu \mathrm{g}$ & 23 & $\mathrm{H}_{2} \mathrm{O}_{(\mathrm{p})}$ & - \\
\hline
\end{tabular}

$\mathbf{H}_{2} \mathbf{O}_{(\mathrm{p})}$ : água destilada; (-): ausência de inibição.

Em estudos realizados por Ranv \& Brimer (1988) e Handjieva (1991), em relação às folhas de Plantago major L., houve o isolamento de um glicosídeo denominado plantamajosídeo. A esse composto foi atribuída a capacidade de inibição de bactérias e fungos, em especial fitopatogênicos, além de efeito inibitório da enzima 5-lipoxigenase, que atua na síntese de peróxidos e leucotrienos $(40,41)$.

Nenhum dos extratos utilizados apresentou atividade antimicrobiana frenta às bactérias Klebsiella pneumoniae, Salmonella typhimurium e Streptococcus pyogenes.

As pesquisas relacionadas à ação antimicrobiana exercida por flavonoides têm crescido com o passar do tempo por meio do conhecimento das estruturas químicas detentoras da atividade antibacteriana. Esses compostos podem inibir o crescimento das bactérias por distintos mecanismos de ação. A inibição de ácidos nucleicos exercida particularmente por flavonoides com hidroxilação no anel B (42), é exemplo desses mecanismos de ação, além da inibição das funções da membrana celular $(43,44)$.

De acordo com Scalbert (1991) (45), Harbone (2000) (46), Veluri e cols. (2004) (47) e Bylka e cols. (2004) (48), assim como os flavonoides, os taninos também podem conferir ação antimicrobiana a extratos.

Os taninos são compostos fenólicos encontrados em diversas partes das plantas como casca, caule, folhas, frutas e raízes (45). O padrão de oxigenação e o grau de polime- rização determinam as propriedades biológicas dos taninos (49). Diversos estudos têm relatado que essas moléculas podem ser tóxicas para fungos filamentosos, leveduras e bactérias (45).

Suas propriedades antimicrobianas presentes na maioria de alimentos de origem vegetal têm sido relatadas (50). Geralmente agem afetando o crescimento bacteriano e viral de diversas formas como, por exemplo, a inibição de enzimas extracelulares e a fosforilação oxidativa (49).

Entre os tipos de taninos, os hidrolisáveis são os que possuem estrutura de poliésteres de compostos de açúcar e ácidos orgânicos (51). Estão presentes na maioria das famílias vegetais e de acordo com estudos, seriam os responsáveis pela ação antioxidante, antiviral, além de atividade antibacteriana (52). Esse metabólito foi um dos encontrados nos extratos etanólico e hidroalcoólico das folhas do Plantago major L., possibilitando possivelmente a sua ação em bactérias como a Staphyloccocus aureus.

\section{CONCLUSÃO}

Pode ser concluído que as folhas do Plantago major L. apresentaram um perfil fitoquímico composto por flavonoides, taninos, saponinas, terpenos, glicosídeos e alcaloi- 
des. A relação soluto-solvente estabelecida entre a planta e os compostos extrativos permitiu um maior aproveitamento de sua ação frente a Staphyloccocus aureus por meio da extração de metabólitos bioativos com ação antimicrobiana, tais como taninos e flavonoides, o que torna Plantago major L. um possível candidato à obtenção de um novo fitoterápico.

\section{REFERÊNCIAS}

1. Pasa MC, Avila G. Ribeirinhos e recursos vegetais: A etnobotânica em Rondonópolis. Interações, Campo Grande, 2010. 11(2):195-204. DOI: 10.1590/S151870122010000200008.

2. Rosa C, Câmara SG, Béria JU. Representações e intenção de uso da fitoterapia na atenção básica à saúde. Ciênc Saúde Coletiva, 2011; 16(1):311-318. DOI: 10.1590/S141381232011000100033.

3. Chin Y-W, Balunas MJ, Chai HB, Kinghorn AD. Drug discovery from natural sources. AAPS J. 2006:E239-E253. DOI: $10.1007 / \mathrm{BF} 02854894$.

4. BRASIL. Ministério da Saúde. Portaria n ${ }^{\circ} 971$, de 03 de maio de 2006. Aprova a Política Nacional de Práticas Integrativas e Complementares (PNPIC) no Sistema Único de Saúde. Diário Oficial da União, 04 de maio de 2006. Seção 1. p. 20-5.

5. Bacchi O, Leitão Filho HF, Aranha C. Plantas invasoras de culturas. Campinas: Instituto Campeiro de Ensino Agrícola. 1984:906.

6. Rocha JF, Rosa MMT, Frade CCM, Diersmann EM. Estudo Anatômico e Histoquímico em Folhas de Plantago major L. e Plantago australis Lam. (PLANTAGINACEAE). Rev Univ Rural, Série Ciências da Vida, Rio de Janeiro, 2002. 22(1):33-41.

7. Velasco-Lezama R, Tapia-Aguilar R, Román-Ramos R, Veja-Avila E, Pérez-Gutiérrez MS. Effect of Plantago major on cell proliferation in vitro. J Ethnopharmacol. 2006; 103(1):36-42. DOI: 10.1016/j.jep.2005.05.050.

8. Chiang LC, Chiang W, Chang MY, Ng LT, Lin CC. Antiviral activity of Plantago major extracts and related compounds in vitro. Antiviral Res. 2002; 55(1):53-62. DOI: 10.1016/S0166-3542(02)00007-4.

9. Sangian H, Faramarzi H, Yazdinezhad A, Mousavi SJ, Zamani Z, Noubarani M, Ramazani A. Antiplasmodial activity of ethanolic extracts of some selected medicinal plants from the northwest of Iran. Parasitol Res. 2013; 112(11):3697-701. DOI: 10.1007/s00436-013-3555-4.

10. Samuelsen AB. The traditional uses, chemical constituents and biological activities of Plantago major L. A review. J. Ethnopharmacol, 2000; 71(1-2):1-21. DOI: 10.1016/S0378-8741(00)00212-9.

11. Baytop T. Therapy with medicinal plants in Turkey. 2.ed. Istanbul-Turkey: Nobel Tip Kitapevleri. 1999.

12. Reina E, Al-Shibani N, Allam E, Gregson KS, Kowolik M, Windisor LJ. The effects of Plantago major on the activation of the neutrophil respiratory burst. J Trad Comp Med. 2013; 3(4):268-72. DOI: 10.4103/2225-4110.119706.

\section{AGRADECIMENTOS}

Os autores agradecem à Prof. ${ }^{\text {a }}$ MSc. Danielle Alves de Melo, Coordenadora do Curso de Farmácia da Faculdade Anhanguera de Brasília, pelo apoio na pesquisa e à Farm. Evalina Costa Souza, Coordenadora do Laboratório da Saúde, pelo incentivo à pesquisa, assim como aos funcionários da instituição.

13. Samuelsen AB, Paulsen BS, Wold JK, Otsuka H, Yamanda H, Espevik T. Isolation end partial characterization of biologically active polysaccharides from Plantago major L. Phytother Res. 1995; 9(1):211-218. DOI: 10.1002/ ptr.2650090312.

14. Duke JA. Handbook of Phytochemical Constituent Grass, Herbs and Other Economic Plants. (ed). CRC Press. 1992.

15. Hung JY, Yang CJ, Tsai, YM, Huang HW, Huang MS. Antiproliferative activy of aucubin is through cell cycle arrest and apoptosis in human nonsmall cell lung cancer A549 cells. Clin Exp Pharmacol Physiol. 2008; 35:9951001. DOI: 10.1111/j.1440-1681.2008.04935.x.

16. 16 Park KS, Chang IM. Antiinflammatory activity of aucubin by inhibition of tumor necrosis factoralpha production in RAW 264.7 cells. Planta Med. 2004. 70:778-9. DOI: $10.1055 / \mathrm{s}-2004-827211$.

17. Matsuzaki Y, Kurokawa N, Terai S, Matsumura Y, Kobaysashi N, Okita K. Cell death induced by baicalein in human hepatocellular carcinoma cell lines. Jap J Cancer Res. 1996; 87:170-177.

18. Motoo Y, Sawabu N. Antitumor effects of saikosaponins, baicalin, and baicalein on human hepatoma-cell lines. Cancer Let. 1994; 86:91-95. DOI: 10.1016/03043835(94)90184-8.

19. Simões CMO, Schenkel EP, Gosmann G, Mello JCP, Mentz LAl, Petrovick PR. Farmacognosia: da planta ao medicamento. $6^{a}$ ed. Porto Alegre/Florianópolis: editora da UFSC. 2007.

20. Recio MC, Giner RM, Rios JL. Structural considerations on the iridoids as anti-inflammatory agentes. Planta Med. 1994; 60:232-234.

21. Huang MT, Smart RC, Wong CQ, Conney AH. Inhibitory effect of curcumin chlorogenic acid, caffeic acid, and ferulic acid on tumor promotion in mouse skin by 12-Otetradecanoylphorbol-13-acetate. Cancer Res. 1988; 48:5941-5946.

22. 22 Liu J. Pharmacology of oleanic acid and ursolic acid. Journal of Ethnopharmacology. 1995. 49:57-68. DOI:10.1016/0378-8741(95)90032-2.

23. Hsu HY, Yang JJ, Linc CC. Effect of oleanolic acid and ursolic acid on inhibiting tumor growth and enhancing the recovery of hematopoietic system postradiation in mice. Cancer Let. 1997; 111:7-13.

24. Oliveira IS. Avaliação da Atividade Antimicrobiana in vitro e in vivo de Croton urucurana Baillon (Sangra D 'Água). [Dissertação]. Cuiabá: Universidade Federal de Mato Grosso. 2007. 
25. Aranson V, Kristinsson K. Do antimicrobials increase the carriage rate of penicillin resistant pneumococci in children? Cross sectional prevalence study. BMG. 1996; 313(7054):387-91. DOI: 10.1136/bmj.313.7054.387.

26. Perez-Bota D, Dimopoulos, G. Are infections due to resistant pathogens associated with a worse outcome in critically ill patients? J Infect. 2003; 47(4):307-16. DOI: 10.1016/S0163-4453(03)00100-2.

27. Pittet D. Infection control and quality health care in the new millennium. Am J Infect Control. 2005; 33(5):25867. DOI: 10.1016/j.ajic.2004.11.004.

28. Rice LB. Federal funding for the study of antimicrobial resistance in nosocomial pathogens: no ESKAPE. J. Infect Dis. 2008:1079-1081. DOI: 10.1086/533452.

29. Lynskey NN, Lawrenson RA, Sriskandan S. New understandings in Streptococcus pyogenes. Curr Opin Infect Dis. 2011; 24(3):196-202. DOI: 10.1097/QCO.0b013e$3283458 f 7 \mathrm{e}$.

30. Nascimento L. Caracterização centesimal, composição química e atividade antioxidante do noni (Morinda citrifolia L.) cultivado no município de Zé Doca-MA [Dissertação]. Rio de Janeiro: Instituto de Tecnologia, Universidade Federal Rural do Rio de Janeiro. 2012.

31. Almeida JCS, Rodrigues TS, Souza KF, Rodrigues-DasDores RG, Nagem TJ. Deteç̧ão de capsaicina em extratos dos frutos verdes e maduros de Capsicum baccatum L. pelas metodologías de cromatografía em camada delgada e histoquímica. Infarma. 2015; 27(2):106-11. DOI: 10.14450/2318-9312.

32. Costa AF. Farmacognosia. 6. ed. Lisboa: Fundação Calouste Gulbenkian. 2002.

33. Bauer AW, Kirby WMM, Sherris JC, Turck M. Antibiotic susceptibility testing by a standardized single disk method. Am J Clin Pathol. 1966; 45(4):493-6.

34. Nascimento GGF, Locatelli J, Freitas PC, Silva GL. Antibacterial activity of plant extracts and phytochemicals on antibiotic-resistant bacteria. Braz J Microbiol 2000; 31(4):247-256. DOI: 10.1590/S151783822000000400003.

35. Kawashty SA, Gamal-El-Din E, Abdalla MF, Saleh NAM. Flavonoids of Plantago species in Egypt. Biocheml Syst Ecol. 1994; 22(7):729-33. DOI: 10.1016/03051978(94)90058-2.

36. Paula CC. Avaliação da atividade antimicrobiana in vitro $\mathrm{e}$ in vivo de Conyza bonariensis (L.) Cronquist (Margaridinha do Campo) e Macrosiphonia velame (A. St.-Hil.) Müll. Arg. (Velame Branco). [Dissertação]. Cuiabá: Faculdade de Ciências Médicas, Universidade Federal de Mato Grosso. 2010.

37. Freitas AG, Costa V, Farias ET, Lima MCA, Sousa IA, Ximenes EA. Atividade antiestafilocócica do Plantago major L. Rev Bras Farmacogn. 2002:64-65. DOI: 10.1590/ S0102-695X2002000300031.

38. Ansolini FC, Tedesco AM, Carpes ST. Atividade antioxidante e antibacteriana dos compostos fenólicos dos extratos de plantas usadas como chás. Braz. J. Food Technol. 2006; 9(3):209-15.
39. Tales DG, Costa MM. Estudo da ação antimicrobiana conjunta de extrato aquoso de Tansagem (Plantago major L. Plantaginaceae) e Romã (Punica granatum L., Punicaceae) e interferência dos mesmos na ação da amoxicilina in vitro. Rev Bras. Pl. Med. 2014; 16(2):323-28. DOI: 10.1590/1983-084X/11 123.

40. Ravn H, Brimer L. Structure and antibacterial activity of plantamajoside, a caffeic acid sugar ester from Plantago major subs. major. Phytochemistry, Biochem Syst Ecol. 1988; 27(11):3433-37. DOI: 10.1016/00319422(88)80744-1.

41. Handjieva N, Spassov S, Bodurova G, Saadi H, Popov S, Pureb O, Zamjansan J. Majoroside, an iridoid glucoside from Plantago major. Phytochemistry. 1991; 30(4):131718. DOI: $10.1016 / \mathrm{S} 0031-9422(00) 95224-5$.

42. Plaper A, Golob M, Hafner I, Oblak M, Solmajr T, Jerala R. Characterization of quercetin binding site on DNA gyrase. Biochem Biophys Res Commun. 2003; 306(2):530-6. DOI: 10.1016/S0006-291X(03)01006-4.

43. Ikigai H, Nakae T, Hara Y, Shimamura T. Bactericidal catechins damage the lipid bilayer. Biochem Biophys Acta. 1993; 1147(1):132-6. DOI: 10.1016/00052736(93)90323-R.

44. 44 Scazzocchio F, D'auria FD, Alessandrini D, Pantanella F. Multifactorial aspectis of antimicrobial activity of propolis. Microbiol Res. 2006. 161(4):327-33. DOI: 10.1016/j.micres.2005.12.003.

45. Scalbert A. Antimicrobial properties of tannins. Phytochemistry. 1991; 30(12):3875-83. DOI: 10.1016/00319422(91)83426-L.

46. Harborne JB. Advances in flavonoid research since. 1992. Phytochemistry. 2000; 55(6):481-504. DOI: 10.1016/ S0031-9422(00)00235-1.

47. Veluri R, Weir TL, Bais HP, Stermitz FR, Vivanco JM. Phytotoxic and antimicrobial activities of catechin derivatives. J Agric Food Chem. 2004; 52(5):1077-82.

48. Bylka W, Matlawska I, Pilewski NA. Natural flavonoids as antimicrobial agents. J Am Nutraceut Assoc. 2004; 7(2):24-31.

49. Schofield P, Mbugua DM, Pell AN. Analysis of condensed tannins: a review. Animal Feed Sci Technol. 2001; 91(1-2):21-40. DOI: 10.1016/S0377-8401(01)00228-0.

50. Chung KT, Stevens JR SE, Lin WF, Wei CI. Growth inhibition of selected food-borne bacteria by tannic acid, propyl gallate and related compounds. Lett Appl Microbiol. 1993; 17(1):29-32. DOI: 10.1111/j.1472-765X.1993. tb01428.x.

51. Simões CMO, Schenkel EP, Gosmann G, Mello JCP, Mentz LA, Petrovick PR. Farmacognosia - da planta ao medicamento. $5^{\text {a }}$ ed. Santa Catarina: Editora da UFSC. 2004.

52. Yang B, Liu P. Composition and Biological Activities of Hydrolyzable Tannins of Fruits of Phyllanthus emblica. J Agric Food Chem. 2014; 62(3):529-41. DOI: 10.1021/ jf404703k. 